Supporting Information

Occurrence, Formation and Oxidative Stress of Emerging Disinfection Byproducts,

\title{
Halobenzoquinones, in Tea
}

Jinxiu Lou, ${ }^{\dagger, \dagger}$ Wei Wang, ${ }^{,}, \dagger, \dagger$ Lizhong Zhu ${ }^{\dagger, \dagger}$

${ }^{\dagger}$ Department of Environmental Science, Zhejiang University, Hangzhou 310058, China

* Zhejiang Provincial Key Laboratory of Organic Pollution Process and Control, Hangzhou 310058, China

* Corresponding author: Wei Wang

Phone/Fax: +8657188982176

E-mail: ww1@zju.edu.cn

Orcid ID: 0000-0001-7066-6076 


\section{Contents}

This material contains 33 pages, 10 tables, 11 figures and 4 texts.

Figure S1. The chemical structures of major tea polyphenols in green tea and black tea.

Figure S2. The DOC of tea as a function of the dosage of tea leaves.

Figure S3. Separation of eight HBQs using UPLC-MS/MS, MRM mode.

Figure S4. MRM chromatograms of TetraC-1,2-BQ in the standard solution of $0.1 \mathrm{ng} / \mathrm{mL}$ (red line) and the tea sample (black line) under the optimal condition (see the Materials and Methods section).

Figure S5. The UPLC-MS/MS spectra of TetraC-1,2-BQ in authentic standard solution and tea. 1) The selected ion chromatogram (XIC) of the authentic standard solution of TetraC-1,2-BQ (blue line), in accordant with that of the tea sample (red line); 2-1) the MS spectrum of tea sample (blue line), in accordance with the theoretical isotope pattern of [TetraC-1,2-BQ-H] (red line); 2-2) the MS/MS spectrum of the most abundant parent isotope $\mathrm{m} / \mathrm{z} 246.87$ in tea sample (blue line), in accordance with the theoretical isotope pattern of [TetraC-1,2-BQ-H] (red line).

Figure S6. The source of TetraC-1,2-BQ in tea made with the local drinking water. TetraC-1,2BQ from tea leaves represents the concentration of TetraC-1,2-BQ in tea made with ultrapure water; TetraC-1,2-BQ from drinking water represents TetraC-1,2-BQ DBP in drinking water; formation of DBPs represents TetraC-1,2-BQ DBP formed from the reaction of tea leaves and residual chlorine in drinking water. Error bars represent standard deviations $(n=3)$.

Figure S7. Semiquinone radicals detected in the reaction between TetraC-1,2-BQ and EGCG. Reaction were carried out in ultrapure water and $[$ TetraC-1,2-BQ] $=0.3 \mathrm{mM}$. (A) $[\mathrm{EGCG}]=0$, $[\mathrm{EGCG}]:[$ TetraC-1,2-BQ $]=0 ; \quad$ (B) $\quad[\mathrm{EGCG}]=0.03 \quad \mathrm{mM}, \quad[\mathrm{EGCG}]:[$ TetraC-1,2-BQ $]=0.1$; (C) $[E G C G]=0.06 \mathrm{mM},[E G C G]:[$ TetraC-1,2-BQ $]=0.2$. The center peak was $\mathrm{g}=2.00538$.

Figure S8. Selected ion chromatograms of the mixtures of 2,6-DCBQ and EGCG analyzed using UPLC-QToF. (A) Conjugates of one EGCG molecule and one 2,6-DCBQ molecule. 
(B) Conjugates of one EGCG molecule and two 2,6-DCBQ molecules. (C) EGCG and (D) 2,6-DCBQ. P1-P4 were present in all the reaction solutions, and P5-P9 were present in only the solution of $[\mathrm{EGCG}]:[2,6-\mathrm{DCBQ}]=1$.

Figure S9. The MS and MS/MS spectra of Peaks P5-P9. (1) P5, P6, P7, P8, and P9 MS are the spectra of the parent ions at retention times of 4.8, 5.4, 5.5, 7.0, and 7.1 min, respectively. (2) P5, P6, P7, P8, and P9 MS/MS are the dependent MS/MS spectra of the parent isotope with highest intensity.

Figure S10. The selected ion chromatogram (XIC) and MS spectra of 2,6-DCBQ in the mixture solution of 2,6-DCBQ and EGCG at different ratio. (1) [EGCG]:[2,6-DCBQ]=1; $[\mathrm{EGCG}]:[2,6-\mathrm{DCBQ}]=10: 1 ;(3)[\mathrm{EGCG}]:[2,6-\mathrm{DCBQ}]=50: 1 ;$ (4) $[\mathrm{EGCG}]:[2,6-\mathrm{DCBQ}]=100: 1$. The left panels are XIC, and the right panels are the MS spectra.

Figure S11. The reaction scheme of EGCG and HBQs.

Table S1. Chemical structure, molecular weight, molecular formula, and purity of the HBQs.

Table S2. Experiment parameters in the preparation of tea.

Table S3. The concentrations of HBQs in tea made at different temperature $(\mu \mathrm{g} / \mathrm{L})$.

Table S4. Chemical structure, molecular weight, molecular formula, and purity of the four tested tea polyphenols.

Table S5. Optimized transaction ion pairs, declustering potential (DP), collision energy (CE), and cell exit potential (CXP) of eight HBQs and four tea polyphenols.

Table S6. The LODs and recoveries of the SPE-UPLC-MS/MS method.

Table S7. HBQ formation potentials of tea leaves (ng/L).

Table S8. Concentration of individual tea polyphenols in four types of tea, $\mathrm{mg} / \mathrm{g}$.

Table S9. Parent ion, retention time, product ion, formula and formation mechanism of conjugates identified in the mixture of EGCG and 2,6-DCBQ.

Table S10. Retention time, chemical formula, and possible structure of each peak present in the mixture of EGCG and 2,6-DCBQ. 
Text S1. Solid phase extraction of HBQs in water samples.

Text S2. The instrument parameters using QTRAP 5500.

Text S3. The instrument parameters using TripleTOF 5600.

Text S4. The instrument parameters using EPR. 
<smiles>Oc1cc(O)c2c(c1)O[C@H](c1ccc(O)c(O)c1)[C@H](O)C2</smiles>

(-)-epicatechin (EC)<smiles>O=C(O[C@@H]1c2cc(O)c(O)cc2Oc2cc(O)cc(O)c21)c1cc(O)c(O)c(O)c1</smiles>

(-)-epigallocatechin gallate (EGCG)<smiles>Oc1cc(O)c2c(c1)O[C@H](c1cc(O)c(O)c(O)c1)[C@H](O)C2</smiles>

(-)-epicatechin gallate(EGC)<smiles>O=C(O[C@H]1Cc2c(O)cc(O)cc2O[C@H]1c1ccc(O)c(O)c1)c1cc(O)c(O)c(O)c1</smiles>

(-)-epigallocatechin (ECG)

\section{Major Tea Polyphenols of Green Tea}

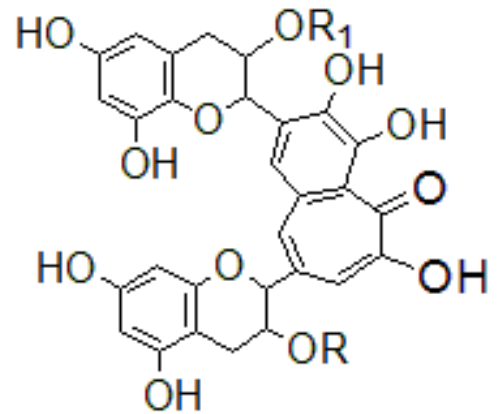

Theaflavin: $\mathrm{R}=\mathrm{R} 1=\mathrm{OH}$

Theaflavin-3-gallate: $\mathrm{R}=\mathrm{Galloy} ; \mathrm{R} 1=\mathrm{OH}$ Theaflavin-3'-gallate: $\mathrm{R}=\mathrm{OH} ; \mathrm{R} 1=$ Galloy Theaflavin-3,3'-digallate: $R=R 1=$ Galloy

\section{Major Tea Polyphenols of Black Tea}

Figure S1. The chemical structures of major tea polyphenols in green tea and black tea. ${ }^{31}$ 

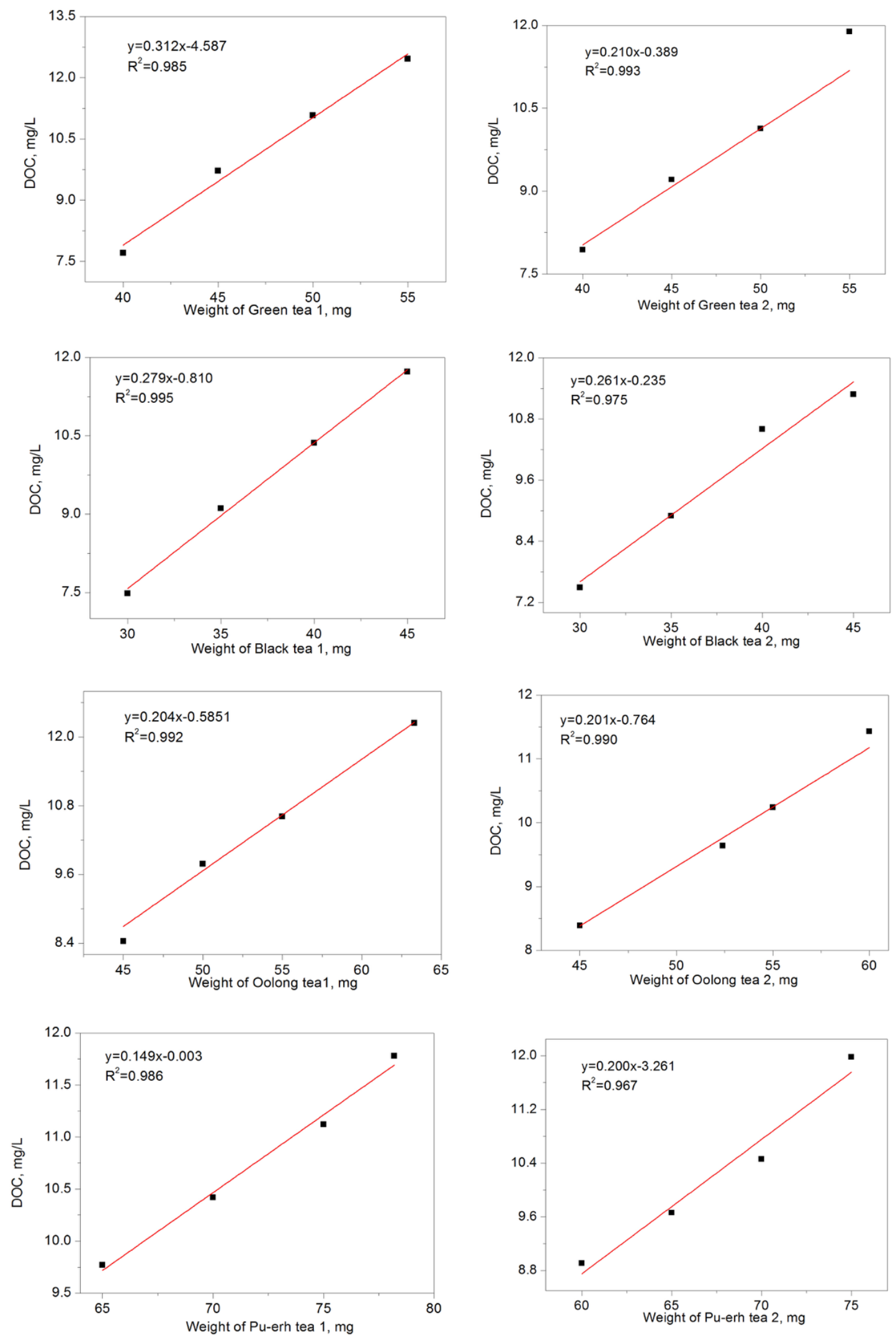

Figure S2. The DOC of tea as a function of the dosage of tea leaves. 


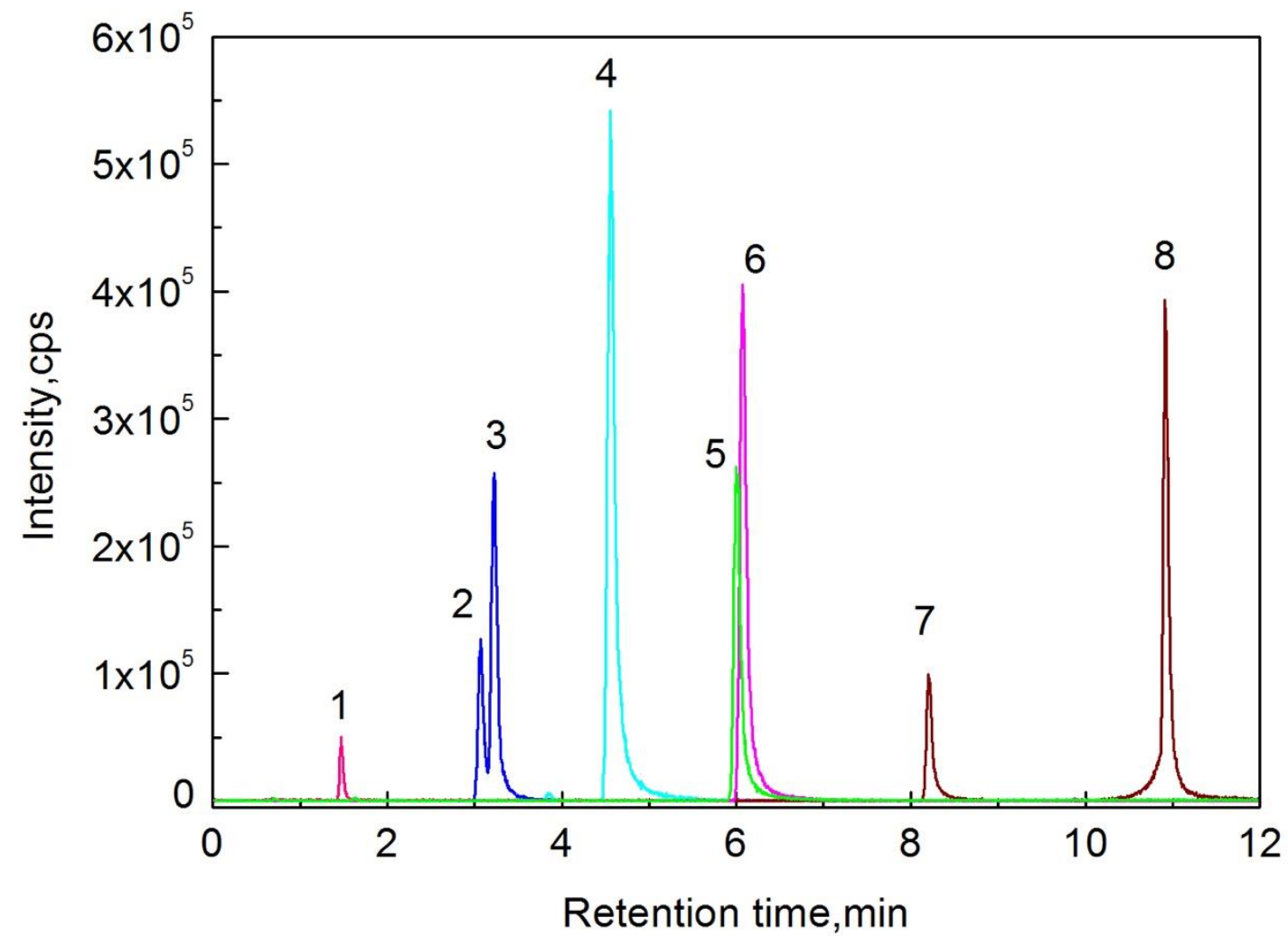

Figure S3. Separation of eight HBQs using UPLC-MS/MS, MRM mode.

1: MCBQ; 2: 2,6-DCBQ; 3: 2,5-DCBQ; 4: 2,6-DBBQ; 5: DCMBQ; 6: TriCBQ;

7: TetraC-1,4-BQ; 8: TetraC-1,2-BQ 


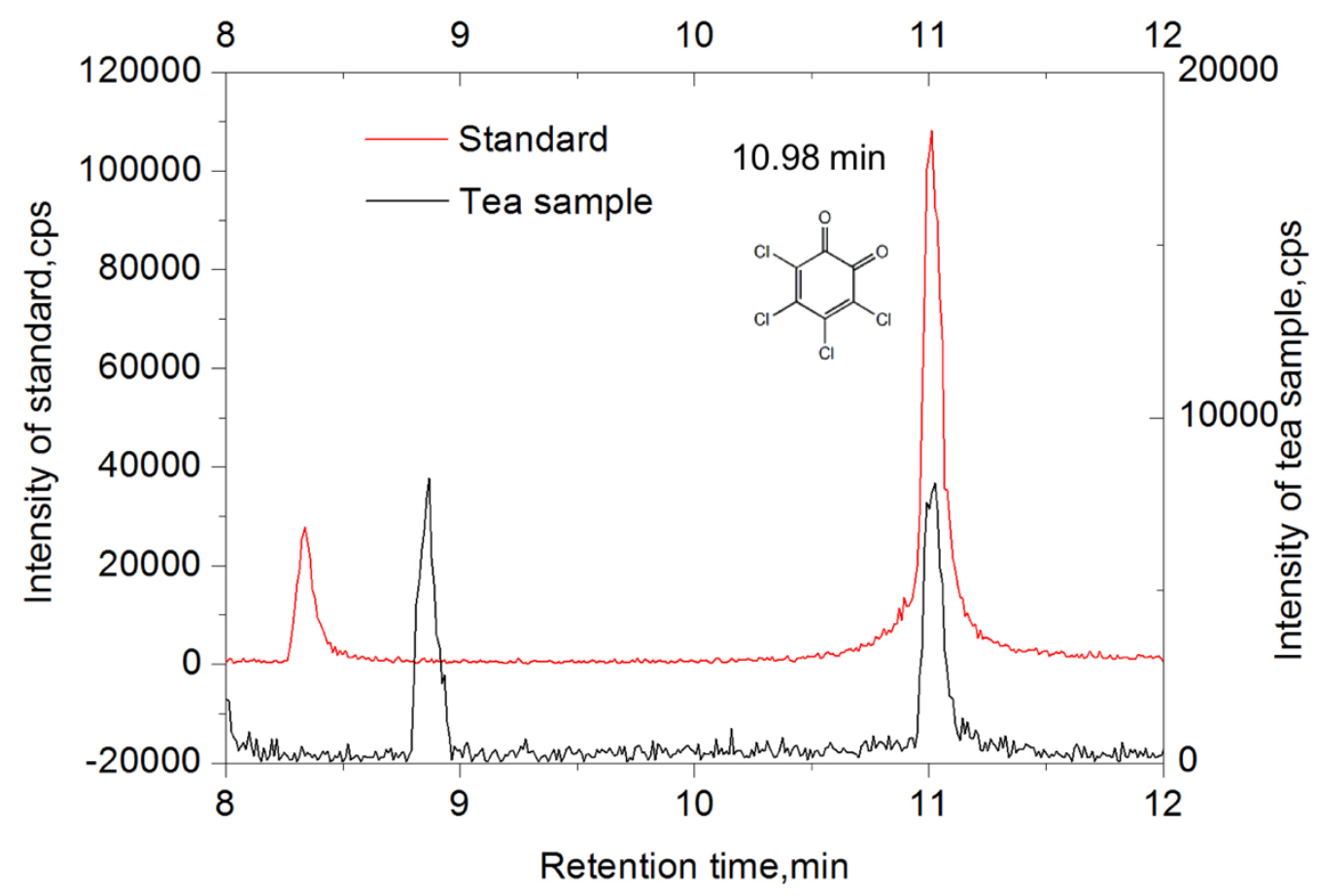

Figure S4. MRM chromatograms of TetraC-1,2-BQ in the standard solution of $0.1 \mathrm{ng} / \mathrm{mL}$ (red line) and the tea sample (black line) under the optimal condition (see the Materials and Methods section). 

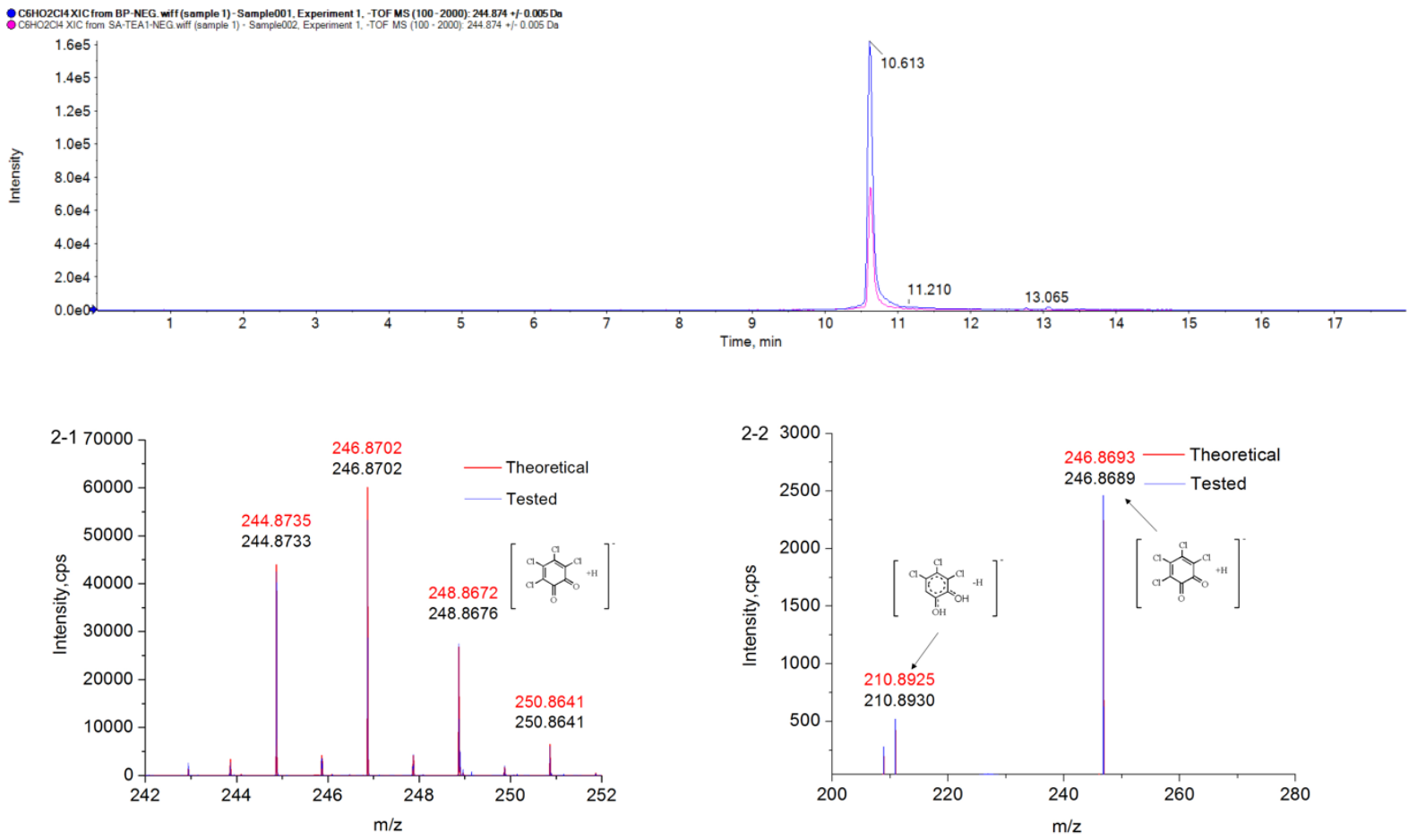

Figure S5. The UPLC-MS/MS spectra of TetraC-1,2-BQ in authentic standard solution and tea. 1) The selected ion chromatogram (XIC) of the authentic standard solution of TetraC-1,2-BQ (blue line), in accordant with that of the tea sample (red line); 2-1) the MS spectrum of tea sample (blue line), in accordance with the theoretical isotope pattern of [TetraC-1,2-BQ-H] (red line); 2-2) the MS/MS spectrum of the most abundant parent isotope $\mathrm{m} / \mathrm{z} 246.87$ in tea sample (blue line), in accordance with the theoretical isotope pattern of [TetraC-1,2-BQ-H] ${ }^{-}$ (red line). 


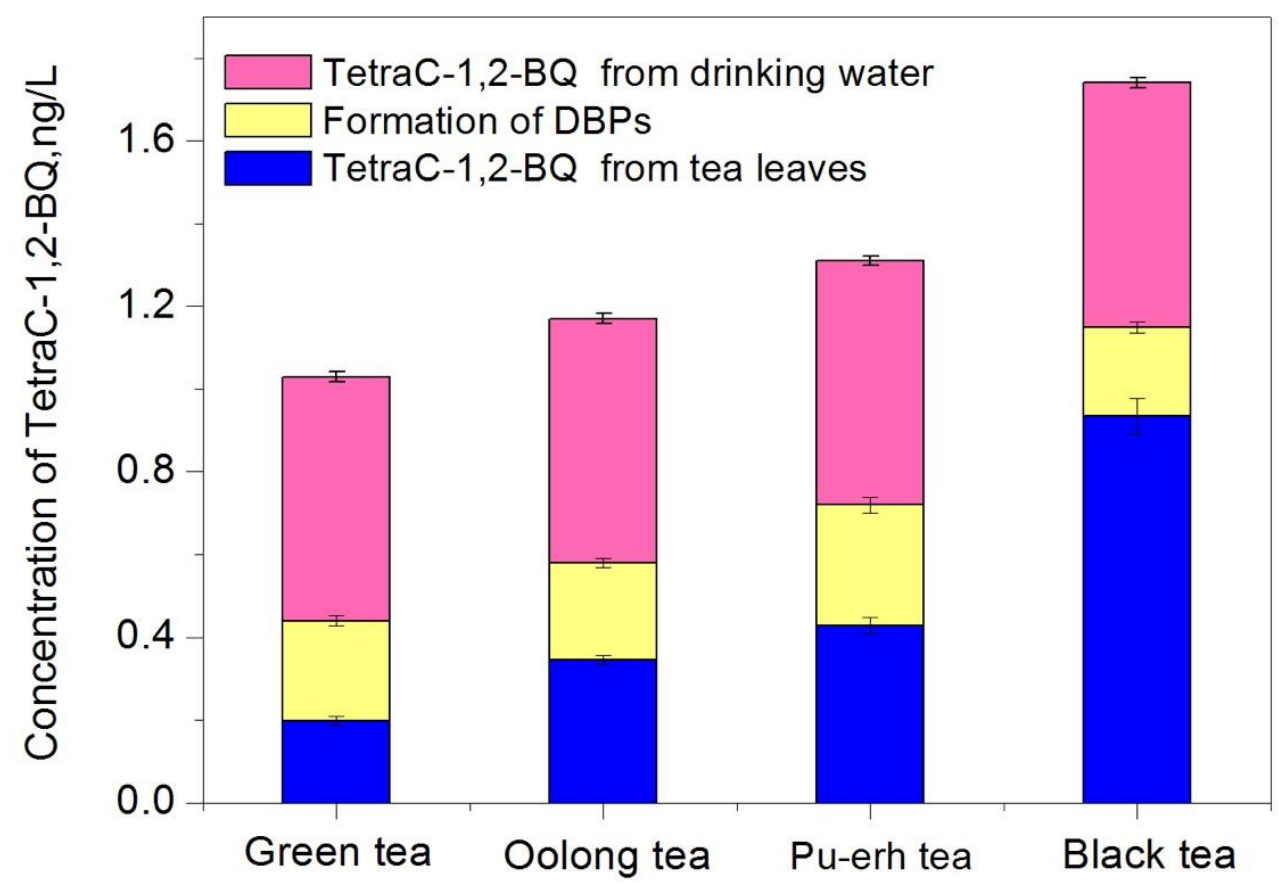

Figure S6. The source of TetraC-1,2-BQ in tea made with the local drinking water. TetraC-1,2BQ from tea leaves represents the concentration of TetraC-1,2-BQ in tea made with ultrapure water; TetraC-1,2-BQ from drinking water represents TetraC-1,2-BQ DBP in drinking water; formation of DBPs represents TetraC-1,2-BQ DBP formed from the reaction of tea leaves and residual chlorine in drinking water. Error bars represent standard deviations $(n=3)$. 

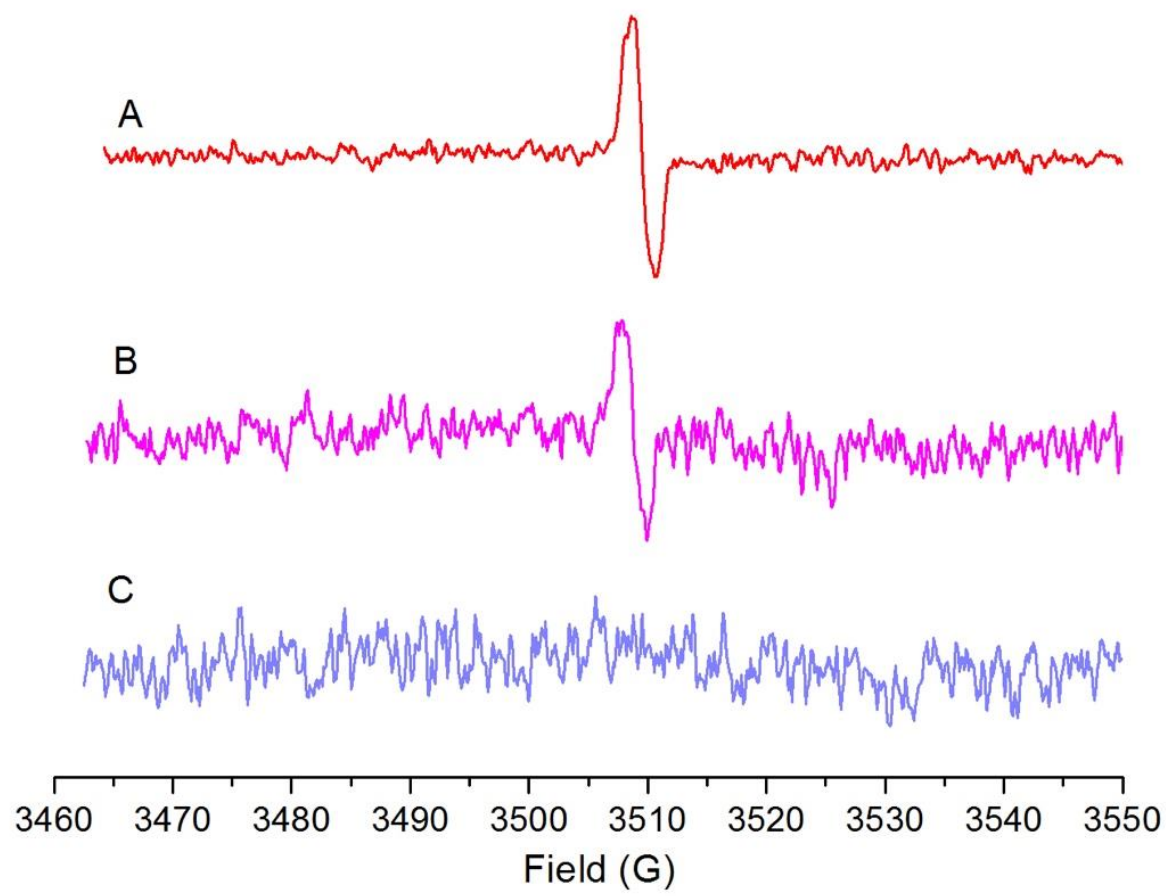

Figure S7. Semiquinone radicals detected in the reaction between TetraC-1,2-BQ and EGCG. Reactions were carried out in ultrapure water and $[$ TetraC-1,2-BQ] $=0.3 \mathrm{mM}$. (A) $[\mathrm{EGCG}]=0$, $[$ EGCG]:[TetraC-1,2-BQ] $=0 ; \quad$ (B) $\quad[\mathrm{EGCG}]=0.03 \quad \mathrm{mM}, \quad[\mathrm{EGCG}]:[$ TetraC-1,2-BQ] $=0.1$; (C) $[\mathrm{EGCG}]=0.06 \mathrm{mM},[\mathrm{EGCG}]:[$ TetraC-1,2-BQ] $=0.2$. The center peak was $\mathrm{g}=2.00538$. 


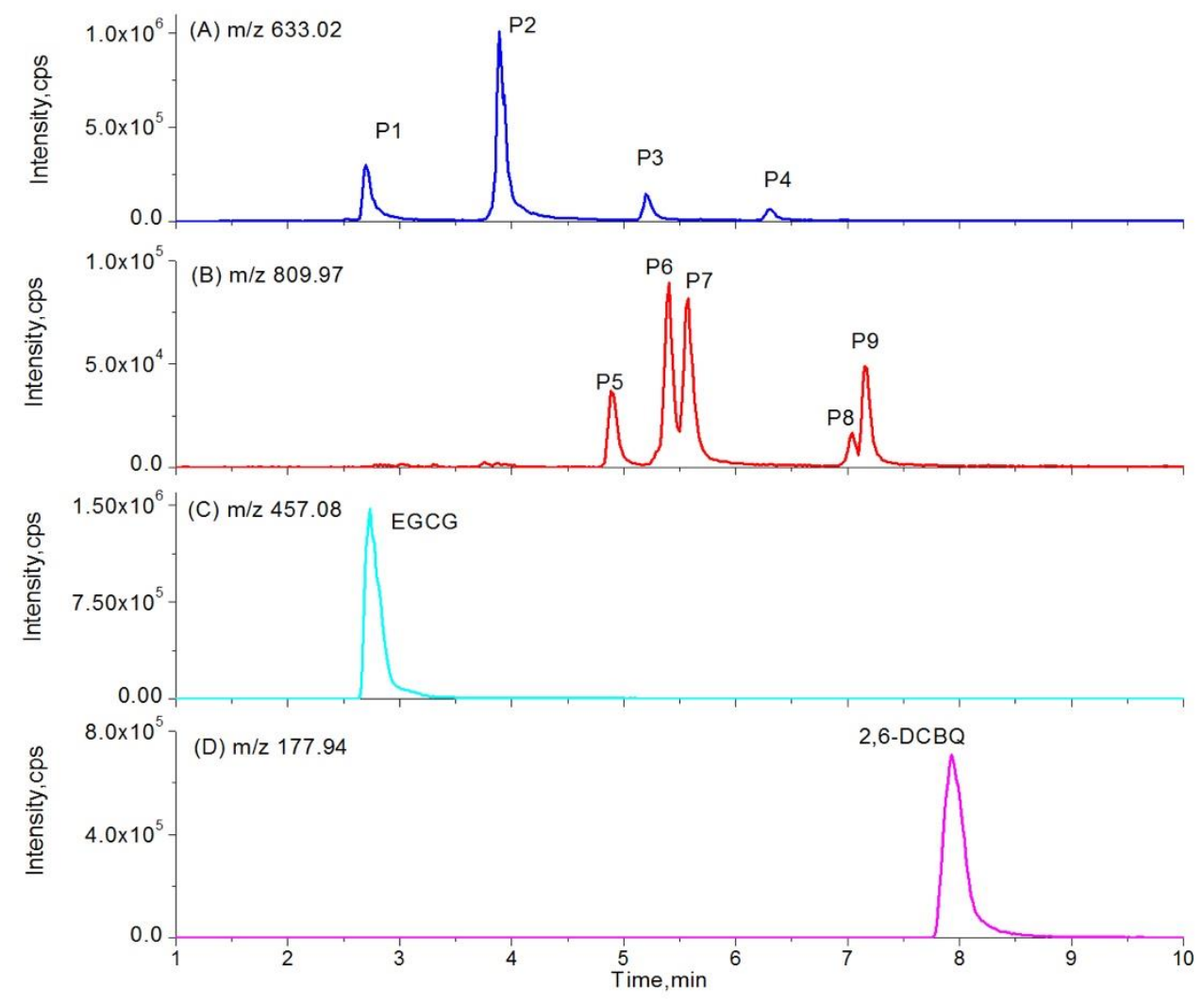

Figure S8. Selected ion chromatograms of the mixtures of 2,6-DCBQ and EGCG analyzed using UPLC-QToF. (A) Conjugates of one EGCG molecule and one 2,6-DCBQ molecule. (B) Conjugates of one EGCG molecule and two 2,6-DCBQ molecules. (C) EGCG and (D) 2,6-DCBQ. P1-P4 were present in all the reaction solutions, and P5-P9 were present in only the solution of [EGCG]:[2,6-DCBQ] $=1$. 

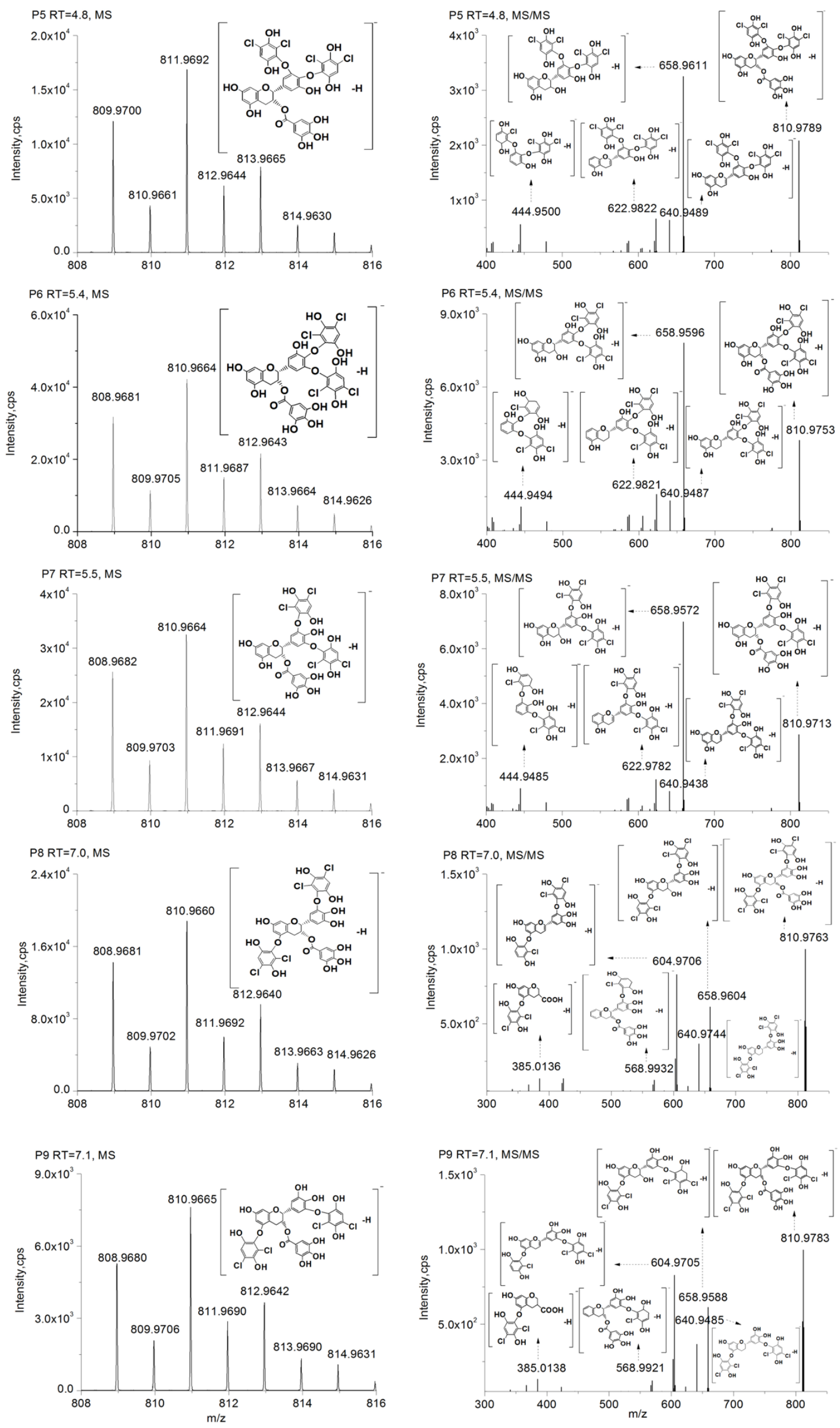
Figure S9. The MS and MS/MS spectra of Peaks P5-P9. (1) P5, P6, P7, P8, and P9 MS are the spectra of the parent ions at retention times of 4.8, 5.4, 5.5, 7.0, and 7.1 min, respectively. (2) P5, P6, P7, P8, and P9 MS/MS are the dependent MS/MS spectra of the parent isotope with highest intensity. 

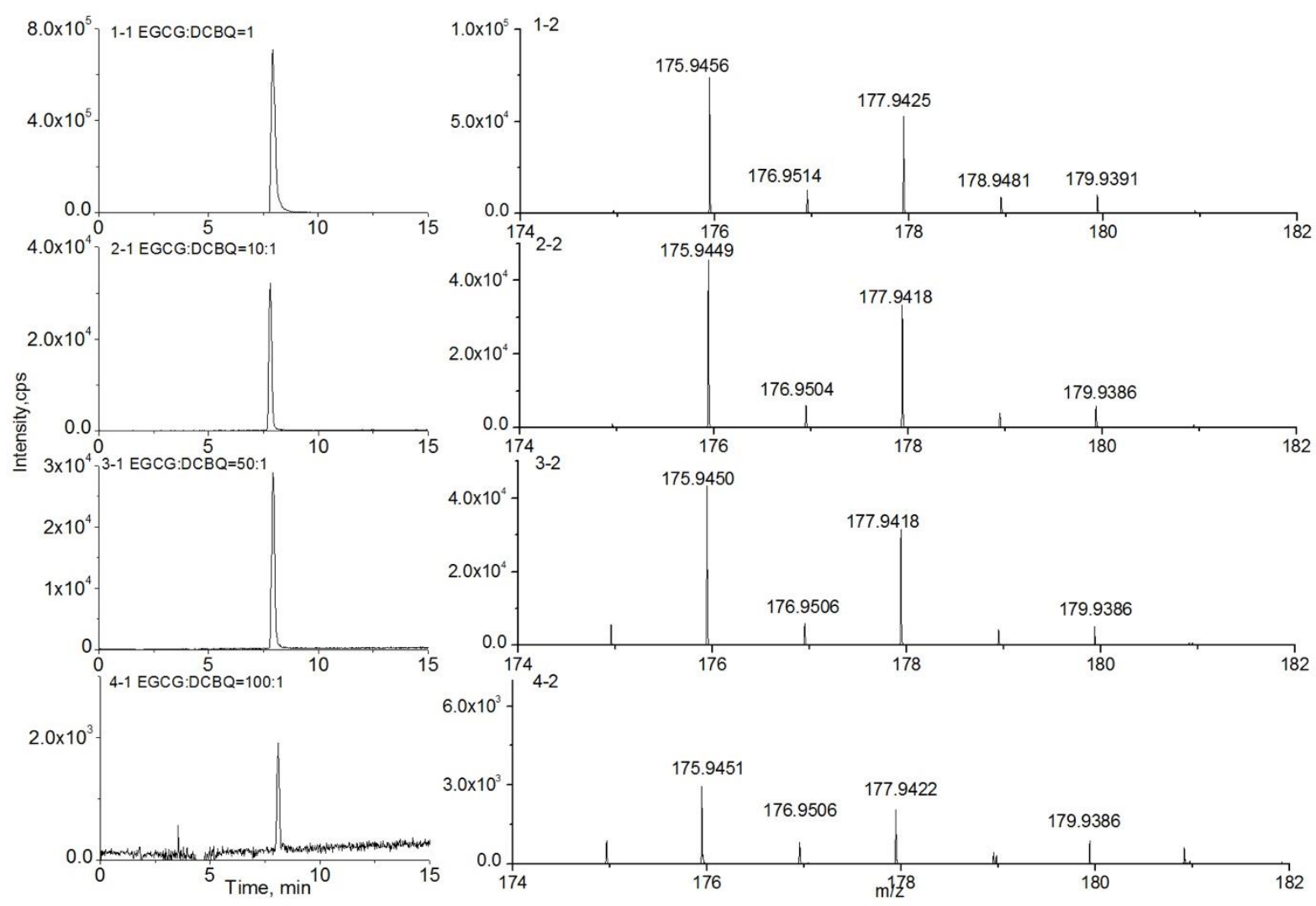

Figure S10. The selected ion chromatogram (XIC) and MS spectra of 2,6-DCBQ in the mixture solution of 2,6-DCBQ and EGCG at different ratio. (1) [EGCG]:[2,6-DCBQ]=1; (2) $[\mathrm{EGCG}]:[2,6-\mathrm{DCBQ}]=10: 1 ;$ (3) $[\mathrm{EGCG}]:[2,6-\mathrm{DCBQ}]=50: 1 ;$ (4) $[\mathrm{EGCG}]:[2,6-\mathrm{DCBQ}]=100: 1$. The left panels are XIC, and the right panels are the MS spectra. 
<smiles>CC(C)C1=CC(=O)C=C(Cl)C1=O</smiles><smiles>CC1(C)C=C(Cl)C(=O)C(Cl)=C1Cl</smiles><smiles>O=C(O[C@H]1Cc2c(O)cc(O)cc2O[C@@H]1c1cc(O)c(O)c(O)c1)c1cc(O)c(O)c(O)c1</smiles><smiles>O=C1C(=O)C(Cl)C(=O)C(Cl)=C1Cl</smiles>

Figure S11. The reaction scheme of EGCG and HBQs. 
Table S1. The chemical structure, molecular weight, molecular formula, and purity of the HBQs.

\begin{tabular}{|c|c|c|c|c|}
\hline HBQs & Structure & $\begin{array}{l}\text { Molecular } \\
\text { Formula }\end{array}$ & $\begin{array}{c}\text { Molecular } \\
\text { weight }\end{array}$ & Purity \\
\hline 2,6-DCBQ & & $\mathrm{C}_{6} \mathrm{H}_{2} \mathrm{Cl}_{2} \mathrm{O}_{2}$ & 176.98 & $\geq 98 \%$ \\
\hline 2,5-DCBQ & & $\mathrm{C}_{6} \mathrm{H}_{2} \mathrm{Cl}_{2} \mathrm{O}_{2}$ & 176.98 & $\geq 98 \%$ \\
\hline 2,6-DBBQ & & $\mathrm{C}_{6} \mathrm{H}_{2} \mathrm{~B}_{\mathrm{r} 2} \mathrm{O}_{2}$ & 263.84 & $\geq 98 \%$ \\
\hline 2,6-DC-3-MBQ & & $\mathrm{C}_{7} \mathrm{H}_{4} \mathrm{Cl}_{2} \mathrm{O}_{2}$ & 191.01 & $\geq 98 \%$ \\
\hline 2,3,6-TriCBQ & & $\mathrm{C}_{6} \mathrm{HCl}_{3} \mathrm{O}_{2}$ & 211.43 & $\geq 98 \%$ \\
\hline MCBQ & & $\mathrm{C}_{6} \mathrm{H}_{3} \mathrm{ClO}_{2}$ & 141.98 & $\geq 95 \%$ \\
\hline TetraC-1,4-BQ & & $\mathrm{C}_{6} \mathrm{Cl}_{4} \mathrm{O}_{2}$ & 243.86 & $\geq 97 \%$ \\
\hline TetraC-1,2-BQ & & $\mathrm{C}_{6} \mathrm{Cl}_{4} \mathrm{O}_{2}$ & 243.86 & $\geq 97 \%$ \\
\hline
\end{tabular}


Table S2. Experiment parameters in the preparation of tea.

\begin{tabular}{ccccc}
\hline Sample & Dose $(\mathrm{mg} / \mathrm{L})$ & DOC $(\mathrm{mg} / \mathrm{L})$ & Cl demand $(\mathrm{mg} / \mathrm{L})$ & $\mathrm{pH}$ before chlorination \\
\hline Oolong tea 1 & 51.89 & 10 & 17.4 & 7.03 \\
Oolong tea 2 & 53.55 & 10 & 18.3 & 7.06 \\
Pu-erh tea 1 & 66.65 & 10 & 21.2 & 7.09 \\
Pu-erh tea 2 & 66.30 & 10 & 22.9 & 7.07 \\
Green tea 1 & 46.75 & 10 & 33.6 & 7.00 \\
Green tea 2 & 48.39 & 10 & 36.7 & 7.01 \\
Black tea 1 & 38.74 & 10 & 28.1 & 7.04 \\
Black tea 2 & 39.21 & 10 & 28.8 & 7.05 \\
Blank & 0 & 0.93 & 0 & 7.00 \\
\hline
\end{tabular}

We first established a linear calibration curve of DOC versus the dose of each tea (Figure S2). Based on the calibration curve, we calculated the appropriate dose of tea to provide a DOC of $10 \mathrm{mg} / \mathrm{L}$. Chlorine demand is tested to determine an appropriate initial chlorine dose and to maintain the free chlorine residual in the range of $1-1.5 \mathrm{mg} / \mathrm{L}$. pH was adjusted to $7.0 \pm 0.2$ using $0.1 \mathrm{~mol} / \mathrm{L} \mathrm{HCl}$. 
Table S3. The concentrations of HBQs in tea made at different temperature $(\mu \mathrm{g} / \mathrm{L})$.

\begin{tabular}{|c|c|c|c|c|c|c|}
\hline HBQs & $\begin{array}{c}\text { Standard } \\
(\mu \mathrm{g} / \mathrm{L})\end{array}$ & $\begin{array}{l}\text { Cold } \\
\text { water } \\
(\mu \mathrm{g} / \mathrm{L})\end{array}$ & $\begin{array}{l}\text { Boiling } \\
\text { water } \\
(\mu \mathrm{g} / \mathrm{L})\end{array}$ & $\begin{array}{c}\text { Deviation }^{1} \\
(\%)\end{array}$ & $\begin{array}{l}\text { Boiling water } \\
\text { and brewed } \\
(\mu \mathrm{g} / \mathrm{L})\end{array}$ & $\begin{array}{c}\text { Deviation }^{2} \\
(\%)\end{array}$ \\
\hline 2,6-DCBQ & 10 & $9.6 \pm 0.1$ & $9.5 \pm 0.2$ & 1.04 & $9.8 \pm 0.3$ & 2.08 \\
\hline 2,5-DCBQ & 10 & $9.3 \pm 0.2$ & $9.1 \pm 0.1$ & 2.15 & $9.4 \pm 0.2$ & 1.08 \\
\hline 2,6-DBBQ & 10 & $9.4 \pm 0.1$ & $9.3 \pm 0.1$ & 1.06 & $9.3 \pm 0.1$ & 1.06 \\
\hline 2,6-DC-3-MBQ & 10 & $9.5 \pm 0.2$ & $9.4 \pm 0.3$ & 1.05 & $9.4 \pm 0.2$ & 1.05 \\
\hline 2,3,6-TriCBQ & 10 & $9.4 \pm 0.2$ & $9.4 \pm 0.2$ & 0.00 & $9.5 \pm 0.3$ & 1.06 \\
\hline MCBQ & 10 & $9.0 \pm 0.3$ & $8.9 \pm 0.1$ & 1.11 & $9.1 \pm 0.1$ & 1.11 \\
\hline TetraC-1,4-BQ & 10 & $9.5 \pm 0.1$ & $9.4 \pm 0.2$ & 1.05 & $9.6 \pm 0.2$ & 1.05 \\
\hline TetraC-1,2-BQ & 10 & $9.6 \pm 0.2$ & $9.4 \pm 0.1$ & 2.08 & $9.7 \pm 0.2$ & 1.04 \\
\hline
\end{tabular}

To examine the effect of water temperature on HBQs in tea, 10 ppb HBQs was spiked in 1) cold water (room temperature, $\left.\left.26^{\circ} \mathrm{C}\right), 2\right)$ boiling water $\left(98.7^{\circ} \mathrm{C}\right)$, and 3) boiling water and further brewed at $80{ }^{\circ} \mathrm{C}$ for $3 \mathrm{~min}$, respectively. Two-hour later, we measured the concentration of HBQs in each solution using UPLC-MS/MS. Duplicate samples were set for each group.

Deviation $^{1}(\%)=\mid$ (concentration of HBQs in cold water- concentration of HBQs in boiling water)/ concentration of HBQs in cold water |.

Deviation $^{2}(\%)=\mid$ (concentration of HBQs in cold water- concentration of HBQs in boiling water and brewed)/ concentration of HBQs in cold water |. 
Table S4. The chemical structure, molecular weight, molecular formula, and purity of the four tested tea polyphenols.

Epigallocatechin


Table S5. Optimized transaction ion pairs, declustering potential (DP), collision energy (CE), and cell exit potential (CXP) of eight HBQs and four tea polyphenols.

\begin{tabular}{|c|c|c|c|c|c|c|}
\hline Analyte & structure & $\begin{array}{c}\mathrm{MRM}(\mathrm{m} / \mathrm{z}) \\
(\mathrm{Q} 1 \rightarrow \mathrm{Q} 3)\end{array}$ & $\mathrm{DP}$ & $\mathrm{CE}$ & $\mathrm{EP}$ & CXP \\
\hline 2,6-DCBQ & & $177 \rightarrow 141$ & -100 & -20 & -10 & -13 \\
\hline 2,5-DCBQ & & $177 \rightarrow 113$ & -100 & -24 & -10 & -13 \\
\hline \multirow[t]{3}{*}{ 2,6-DBBQ } & & $267 \rightarrow 79,81$ & -100 & -50 & -10 & -10 \\
\hline & & $265 \rightarrow 79$ & -100 & -50 & -10 & -10 \\
\hline & & $269 \rightarrow 81$ & -100 & -50 & -10 & -10 \\
\hline \multirow[t]{2}{*}{ 2,6-DC-3-MBQ } & & $191 \rightarrow 127$ & -85 & -24 & -11 & -11 \\
\hline & & $191 \rightarrow 155$ & -85 & -20 & -10 & -11 \\
\hline \multirow[t]{3}{*}{ 2,3,6-TriCBQ } & & $211 \rightarrow 175$ & -80 & -18 & -11 & -10 \\
\hline & & $211 \rightarrow 147$ & -80 & -20 & -11 & -10 \\
\hline & & $142.9 \rightarrow 78.9$ & -80 & -22 & -10 & -10 \\
\hline MCBQ & & $142.9 \rightarrow 51$ & -60 & -30 & -10 & -10 \\
\hline TetraC-1,4-BQ & & $245 / 247 \rightarrow 35$ & -75 & -55 & -10 & -5 \\
\hline \multirow[t]{2}{*}{ TetraC-1,2-BQ } & & $247 \rightarrow 211$ & -75 & -21 & -10 & -8 \\
\hline & & $247 \rightarrow 209$ & -75 & -21 & -10 & -8 \\
\hline
\end{tabular}


Gallic acid<smiles>O=C(O)c1cc(O)c(O)c(O)c1</smiles>

$\begin{array}{lrrrr}169 \rightarrow 125 & -45 & -22 & -10 & -10 \\ 169 \rightarrow 79.1 & -78 & -28 & -10 & -11\end{array}$

Epicatechin $289 \rightarrow 245$-105 -22<smiles>O=C(c1cc(O)c(O)c(O)c1)C1Cc2c(O)cc(O)cc2OC1c1ccc(O)c(O)c1</smiles>

Epigallocatechin


Table S6. The LODs and recoveries of the SPE-UPLC-MS/MS method.

\begin{tabular}{ccccc}
\hline \multirow{2}{*}{ Analytes } & \multicolumn{2}{c}{ Tap water } & \multicolumn{2}{c}{ Tea infusion } \\
\cline { 2 - 5 } & LOD (ng/L) & Recovery (\%) & LOD (ng/L) & Recovery (\%) \\
\hline 2,6-DCBQ & 0.3 & $96 \pm 4$ & 0.2 & $26 \pm 12$ \\
2,5-DCBQ & 0.9 & $76 \pm 6$ & 0.8 & $29 \pm 9$ \\
2,6-DBBQ & 0.2 & $102 \pm 3$ & 0.2 & $23 \pm 8$ \\
2,6-DC-3-MBQ & 0.4 & $69+4$ & 0.6 & $31+11$ \\
2,3,6-TriCBQ & 0.6 & $101 \pm 2$ & 0.3 & $27 \pm 6$ \\
MCBQ & 2.4 & $58 \pm 7$ & 2.6 & $22 \pm 7$ \\
TetraC-1,4-BQ & 0.9 & $86 \pm 5$ & 0.8 & $63 \pm 9$ \\
TetraC-1,2-BQ & 0.2 & $95 \pm 3$ & 0.2 & $91 \pm 5$ \\
\hline
\end{tabular}

To determine the LOD of the SPE-UPLC-MS/MS method, seven replicate samples were spiked with chemical standards to give a final spiked concentration of $20 \mathrm{ng} / \mathrm{L}$. These samples were then subjected to SPE and LC-MS/MS analysis, and the standard deviation (SD) of each analyte from the replicates was calculated. LOD was calculated based on the following formula: $\mathrm{LOD}=\mathrm{t} \times \mathrm{SD}$, where $\mathrm{t}=3.14$ for 6 degrees of freedom.

The recoveries of the analytes during SPE were determined based on the peak areas obtained for the samples spiked with the standards before the SPE (pre-extraction spiked samples) and after the SPE (postextraction spiked samples). Three sets of samples were prepared, and each set contained triplicate samples.

Set 1 consisted of tap water samples, subjected to SPE, reconstituted, and then spiked with the mixed standards to yield a final spiked concentration of $30 \mathrm{ng} / \mathrm{mL}$. Set 2 was tap water samples, subjected to SPE, and reconstituted without spiking of the standards. Set 3 was prepared by spiking the mixed standards in tap water samples (30 ng/L), which were subjected to the SPE and LC-MS/MS analysis. Three average peak areas for each analyte $\left(\mathbf{A}_{\text {set1 }}, \mathbf{A}_{\text {set2, }}\right.$ and $\mathbf{A}_{\text {set3) }}$ ) were obtained. The recoveries were determined based on the formula, recovery $=\left(\mathbf{A}_{\text {set3 }}-\mathbf{A}_{\text {set2 }}\right) \times \mathbf{1 0 0} /\left(\mathbf{A}_{\text {set1 }}-\mathbf{A}_{\text {set2 }}\right)$.

The LODs of HBQs in tap water were in the range of 0.2 to $2.4 \mathrm{ng} / \mathrm{L}$, and the recoveries were between $58 \%$ and $102 \%$. The LODs of HBQs in tea were $0.2-2.6 \mathrm{ng} / \mathrm{L}$, and the recoveries were $22 \%-91 \%$. The recoveries of HBQs in tea seemed to be relatively low since HBQs 
reacted with tea polyphenols. All data reported in the study are higher than the quantification limits, which are three times of the LODs. 
Table S7. HBQ formation potentials of tea leaves (ng/L).

\begin{tabular}{ccccccc}
\hline Type & 2,6-DCBQ & MCBQ & TriCBQ & TetraC-1,2- & TetraC- & Sum \\
\hline Oolong tea & $160.8 \pm 11.7$ & $102.3 \pm 6.8$ & $0.5 \pm 0.1$ & $7.9 \pm 0.5$ & nd & $271.5 \pm 19.0$ \\
Pu-erh tea & $1251.7 \pm 58.2$ & $462.7 \pm 19.1$ & $1.8 \pm 0.1$ & $23.9 \pm 2.0$ & nd & $1740.1 \pm 79.4$ \\
Black tea & $1922.6 \pm 49.7$ & $683.2 \pm 10.8$ & $2.3 \pm 0.1$ & $11.7 \pm 0.4$ & $0.6 \pm 0.1$ & $2620.5 \pm 61.0$ \\
Green tea & $3045.9 \pm 60.7$ & $726.9 \pm 11.6$ & $1.8 \pm 0.1$ & $6.2 \pm 0.5$ & nd & $3780.7 \pm 72.8$ \\
\hline
\end{tabular}


Table S8. Concentration of individual tea polyphenols in four types of tea, mg/g.

\begin{tabular}{cccccc}
\hline Sample & GA & EC & ECG & EGCG & Sum \\
\hline Green tea & $7.8 \pm 0.5$ & $2.2 \pm 0.1$ & $5.6 \pm 0.3$ & $18.6 \pm 0.9$ & $34.2 \pm 1.8$ \\
Oolong tea & $0.8 \pm 0.0$ & $1.0 \pm 0.1$ & $2.3 \pm 0.1$ & $1.3 \pm 0.2$ & $5.4 \pm 0.4$ \\
Black tea & $10.4 \pm 0.6$ & $1.2 \pm 0.1$ & $3.9 \pm 0.3$ & $5.7 \pm 0.5$ & $21.2 \pm 1.5$ \\
Pu-erh tea & $21.3 \pm 1.3$ & $1.7 \pm 0.1$ & $2.8 \pm 0.3$ & $3.2 \pm 0.1$ & $29.0 \pm 1.8$ \\
\hline
\end{tabular}

Values are given as $\mathrm{mg} / \mathrm{g}$. 
Table S9. Parent ion, retention time, product ion, formula and formation mechanism of conjugates identified in the mixture of EGCG and 2,6-DCBQ.

\begin{tabular}{|c|c|c|c|c|c|}
\hline No. & Parent ion & $\begin{array}{l}\text { Retention } \\
\text { time(min) }\end{array}$ & $\begin{array}{l}\text { Product } \\
\text { ion }\end{array}$ & Formula & Formation \\
\hline \multirow{4}{*}{1} & \multirow{4}{*}{$\begin{array}{c}633.02 \\
(\mathrm{P} 1, \mathrm{P} 2, \mathrm{P} 3)\end{array}$} & 2.7 & 481.0142 & {$\left[\mathrm{C}_{21} \mathrm{H}_{16} \mathrm{Cl}_{2} \mathrm{O}_{9}-\mathrm{H}\right]^{-}$} & $\begin{array}{c}\text { ECCG }+2,6-\text { DCBQ }- \text { Galloyl }+ \\
\text { OH }\end{array}$ \\
\hline & & 3.9 & 463.0028 & {$\left[\mathrm{C}_{21} \mathrm{H}_{14} \mathrm{Cl}_{2} \mathrm{O}_{8} \cdot-\mathrm{H}\right]^{-}$} & $\mathrm{ECCG}+2,6-\mathrm{DCBQ}-$ Galloyl \\
\hline & & 5.2 & 300.9686 & {$\left[\mathrm{C}_{12} \mathrm{H}_{8} \mathrm{Cl}_{2} \mathrm{O}_{5}-\mathrm{H}\right]^{-}$} & 2,6-DCBQ + B ring \\
\hline & & & 267.0068 & {$\left[\mathrm{C}_{12} \mathrm{H}_{9} \mathrm{ClO}_{5} \cdot \mathrm{H}\right]^{-}$} & 2,6-DCBQ $+\mathrm{B}$ ring $-\mathrm{Cl}$ \\
\hline \multirow{4}{*}{2} & \multirow{4}{*}{$\begin{array}{l}633.02 \\
(\mathrm{P} 4)\end{array}$} & \multirow{4}{*}{6.3} & 427.0260 & {$\left[\mathrm{C}_{21} \mathrm{H}_{13} \mathrm{ClO}_{8}-\mathrm{H}\right]^{-}$} & $\begin{array}{c}\mathrm{ECCG}+2,6-\mathrm{DCBQ}-\text { Galloyl }- \\
\mathrm{Cl}\end{array}$ \\
\hline & & & 409.0146 & {$\left[\mathrm{C}_{21} \mathrm{H}_{11} \mathrm{ClO}_{7}-\mathrm{H}\right]^{-}$} & $\begin{array}{c}\mathrm{ECCG}+2,6-\mathrm{DCBQ}-\text { Galloyl }- \\
\mathrm{Cl}-\mathrm{OH}\end{array}$ \\
\hline & & & 336.9696 & {$\left[\mathrm{C}_{15} \mathrm{H}_{8} \mathrm{Cl}_{2} \mathrm{O}_{5}-\mathrm{H}\right]^{-}$} & A ring $+\mathrm{C}$ ring $+2,6-\mathrm{DCBQ}$ \\
\hline & & & 288.9919 & {$\left[\mathrm{C}_{15} \mathrm{H}_{11} \mathrm{Cl}_{2} \mathrm{O}_{4}-\mathrm{H}\right]^{-}$} & $\begin{array}{c}\text { A ring }+\mathrm{C} \text { ring }+2,6-\mathrm{DCBQ}- \\
\mathrm{OH}-\mathrm{Cl}\end{array}$ \\
\hline \multirow{4}{*}{3} & \multirow{4}{*}{$\begin{array}{c}810.97 \\
(\mathrm{P} 5, \mathrm{P} 6, \mathrm{P} 7)\end{array}$} & & 658.9611 & {$\left[\mathrm{C}_{27} \mathrm{H}_{20} \mathrm{Cl}_{4} \mathrm{O}_{11}-\mathrm{H}\right]^{-}$} & $\begin{array}{c}\mathrm{ECCG}+2 \times 2,6-\mathrm{DCBQ}- \\
\text { Galloyl }+\mathrm{OH}\end{array}$ \\
\hline & & $\begin{array}{l}4.8 \\
5.4\end{array}$ & 640.9489 & {$\left[\mathrm{C}_{27} \mathrm{H}_{18} \mathrm{Cl}_{4} \mathrm{O}_{10}-\mathrm{H}\right]^{-}$} & $\begin{array}{c}\mathrm{ECCG}+2 \times 2,6-\mathrm{DCBQ}- \\
\text { Galloyl }\end{array}$ \\
\hline & & 5.5 & 622.9822 & {$\left[\mathrm{C}_{27} \mathrm{H}_{16} \mathrm{Cl}_{4} \mathrm{O}_{9}-\mathrm{H}\right]^{-}$} & $\begin{array}{c}\mathrm{ECCG}+2 \times 2,6-\mathrm{DCBQ}- \\
\text { Galloyl }-\mathrm{OH}\end{array}$ \\
\hline & & & 444.9500 & {$\left[\mathrm{C}_{18} \mathrm{H}_{13} \mathrm{Cl}_{3} \mathrm{O}_{7}-\mathrm{H}\right]^{-}$} & $\mathrm{B}$ ring $+2 \times 2,6-\mathrm{DCBQ}-\mathrm{Cl}$ \\
\hline \multirow{3}{*}{4} & \multirow{3}{*}{$\begin{array}{l}810.97 \\
(\mathrm{P} 8, \mathrm{P} 9)\end{array}$} & \multirow{3}{*}{$\begin{array}{l}7.0 \\
7.1\end{array}$} & 604.9706 & {$\left[\mathrm{C}_{27} \mathrm{H}_{17} \mathrm{Cl}_{3} \mathrm{O}_{10}-\mathrm{H}\right]^{-}$} & $\begin{array}{c}\mathrm{ECCG}+2 \times 2,6-\mathrm{DCBQ}- \\
\text { Galloyl }-\mathrm{Cl}\end{array}$ \\
\hline & & & 568.9932 & {$\left[\mathrm{C}_{28} \mathrm{H}_{23} \mathrm{ClO}_{11}-\mathrm{H}\right]^{-}$} & $\begin{array}{c}\mathrm{ECCG}+2,6-\mathrm{DCBQ}-2 \mathrm{OH}- \\
\mathrm{Cl}\end{array}$ \\
\hline & & & 385.0138 & {$\left[\mathrm{C}_{16} \mathrm{H}_{12} \mathrm{Cl}_{2} \mathrm{O}_{7}-\mathrm{H}\right]^{-}$} & $\begin{array}{c}\text { A ring }+\mathrm{C} \text { ring }+2,6-\mathrm{DCBQ}+ \\
\mathrm{COOH}\end{array}$ \\
\hline
\end{tabular}


The product ions of $\mathrm{P} 1, \mathrm{P} 2$ and $\mathrm{P} 3$ had the same fragment with a mass accuracy better than 0.001 , the exact $\mathrm{m} / \mathrm{z}$ of $\mathrm{P} 1$ is listed in the table to elucidate the formation mechanism. Similar treatment is conducted for the group of P5, P6 and P7, and the group P8 and P9. 
Table S10. Retention time, chemical formula, and possible structure of each peak present in the mixture of EGCG and 2,6-DCBQ.

\begin{tabular}{|c|c|c|c|c|}
\hline No. & $\begin{array}{l}\text { Retention } \\
\text { time (min) }\end{array}$ & Name & Formula & Structure \\
\hline 1 & 2.7 & EGCG-3-DCBQ & $\mathrm{C}_{28} \mathrm{H}_{20} \mathrm{Cl}_{2} \mathrm{O}_{13}$ & \\
\hline 2 & 2.8 & EGCG & $\mathrm{C}_{22} \mathrm{H}_{18} \mathrm{O}_{11}$ & \\
\hline 3 & 3.9 & EGCG-5-DCBQ & $\mathrm{C}_{28} \mathrm{H}_{20} \mathrm{Cl}_{2} \mathrm{O}_{13}$ & \\
\hline 4 & 4.8 & EGCG-3,4-2-DCBQ & $\mathrm{C}_{34} \mathrm{H}_{22} \mathrm{Cl}_{4} \mathrm{O}_{15}$ & \\
\hline 5 & 5.2 & EGCG-4-DCBQ & $\mathrm{C}_{28} \mathrm{H}_{20} \mathrm{Cl}_{2} \mathrm{O}_{13}$ & \\
\hline 6 & 5.4 & EGCG-4,5-2-DCBQ & $\mathrm{C}_{34} \mathrm{H}_{22} \mathrm{Cl}_{4} \mathrm{O}_{15}$ & \\
\hline
\end{tabular}




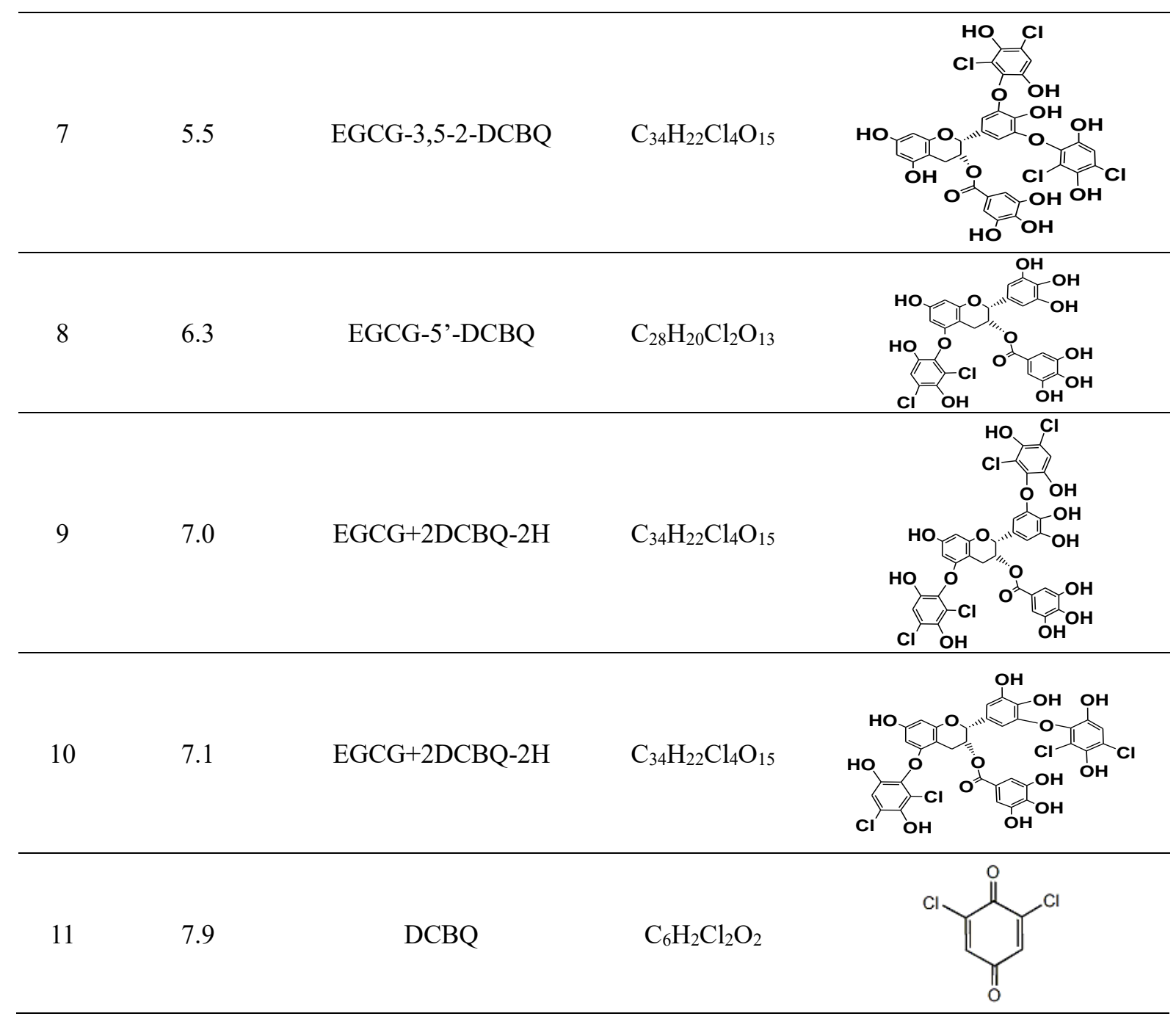


Text S1. Solid phase extraction of HBQs in water samples. Samples were concentrated using solid phase extraction (SPE) with Waters Oasis HLB cartridges (6 mL, $200 \mathrm{mg}$ per cartridge) mounted in a VISIPREP SPE manifold (Supelco, Bellefonte, PA) with flow control liners. Prior to sample loading, each HLB cartridge was prepared with one rinse of $6 \mathrm{~mL}$ of methanol containing $0.25 \%$ FA followed by two washes of $6 \mathrm{~mL}$ of acidified water with $0.25 \% \mathrm{FA}$. Each sample $(500 \mathrm{~mL})$ was forced through the cartridges at a flow rate of approximately $8 \mathrm{~mL} / \mathrm{min}$. After sample loading, the cartridges were washed with $6 \mathrm{~mL}$ of acidified water $(0.25 \% \mathrm{FA})$ and $6 \mathrm{~mL}$ of methanol/water (v/v 50/50, with $0.25 \% \mathrm{FA})$ and then dried for $10 \mathrm{~min}$ under vacuum. The analytes on the cartridge were eluted with $6 \mathrm{~mL}$ of methanol $(0.25 \% \mathrm{FA})$, and the methanol extract was evaporated down to $100 \mu \mathrm{L}$ under a gentle nitrogen stream and then reconstituted with water $(0.25 \% \mathrm{FA})$ to a final volume of $500 \mu \mathrm{L}$ water/methanol (v/v 80/20, with $0.25 \% \mathrm{FA}$ ). It is important not to completely dry the extract during evaporation to avoid loss of the analytes. 
Text S2. The instrument parameters using QTRAP 5500. A triple quadrupole ion-trap tandem mass spectrometer (QTRAP 5500, AB Sciex, Concord, ON) with multiple-reaction monitoring (MRM) methods was used in our experiment. The instrument parameters of the methods were set as below: ionspray voltage, $-4500 \mathrm{~V}$; temperature, $450{ }^{\circ} \mathrm{C}$; curtain gas, 30.0 psi; collision gas, medium (9.0 psi); gas I (nebulizer gas), 50.0 psi; gas II (heater gas), 50.0 psi; entrance potential, $-10.0 \mathrm{psi}$; and accumulation time, $200 \mathrm{~ms}$. 
Text S3. The instrument parameters using TripleTOF 5600. A quadrupole time-of-flight mass spectrometer (QToF MS; AB SCIEX TripleTOF 5600 plus system, AB SCIEX, Framingham, USA) was coupled with UPLC to obtain the isotope pattern and fragment information of the conjugation products of HBQs and tea polyphenols. To identify all possible unknown conjugates and to reduce the background interference, we developed an informationdependent acquisition (IDA) method. In the, we set two simultaneous experiments: (1) negative ToF MS survey scan and (2) negative product ion scan. The optimal MS conditions were as follows: source voltage, $-4500 \mathrm{~V}$; source temperature, $550^{\circ} \mathrm{C}$, gas I, 50 arbitrary units, gas II, 50 arbitrary units; curtain gas, 35 arbitrary units; DP, $-100 \mathrm{~V}$; CE, $-10 \mathrm{~V}$; and for MS/MS acquisition mode, ion release delay (IRD) of 67 and ion release width of 25 . The IDA analysis was performed for the eight most intense ions in a full scan cycle $(1 \mathrm{~s})$. The $\mathrm{m} / \mathrm{z}$ scan range of precursor ions and product ions were set to 100-2000 Da and 50-2000 Da, respectively. The CE voltage was set to 20,40 , and $60 \mathrm{eV}$. The exact mass calibration was automatically performed before each analysis by employing automated calibration delivery.

Text S4. The instrument parameters for EPR. The EPR analysis of cell samples was performed at $110 \mathrm{k}$ with nitrogen gas at a flow rate of $200 \mathrm{~L} /$ hour. Fifty microliters of the cell suspension was transferred to gas permeable Teflon tubing ( $1 \mathrm{~mm}$ i.d., $8 \mathrm{~cm}$ length) for the scan. The $\mathrm{Q}$ value was $3217 \pm 20$, the microwave power was $20 \mathrm{~mW}$, and the scan frequency was $9.02 \mathrm{GHz}$. The scan range was from 3200 to $3230 \mathrm{G}$, the modulation amplitude was $1.0 \mathrm{G}$, and the sweep time was $40 \mathrm{~s}$. 